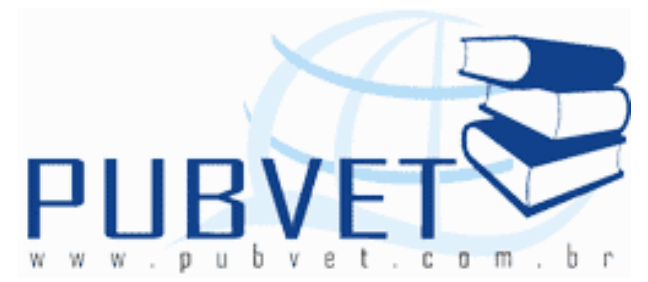

PUBVET, Publicações em Medicina Veterinária e Zootecnia.

\title{
Avaliação in vitro de óleos essenciais na inibição de Staphylococcus aureus e Escherichia coli
}
Virgínia de Queiroz Melo ${ }^{2}$, Letícia Ríspoli Coelho ${ }^{1,2}$, Roberta Torres de Melo ${ }^{1,2}$, Guilherme Paz Monteiro², Priscila Christen Nalevaiko², Eliane Pereira Mendonça ${ }^{1,2}$, Daise Aparecida Rossi ${ }^{1,2}$

${ }^{1}$ Programa de Pós-Graduação em Medicina Veterinária da Universidade Federal de Uberlândia;

${ }^{2}$ Laboratório de Biotecnologia Animal e Aplicada da Universidade Federal de Uberlândia.

\section{Resumo}

Este trabalho foi realizado com o objetivo de avaliar o efeito in vitro de óleos essenciais na inibição de Escherichia coli ATCC 25922 e Staphylococcus aureus ATCC 25923. Foram testados os óleos essenciais de alecrim (Rosmarinus officinalis), manjerona (Origanum majorana L.), manjericão (Ocimum basilicum L.), eucalipto (Eucaliptus citriodora), citronela (Cymbopogon winterianus) e capim-limão (Cymbopogon citratus), previamente extraídos pela técnica de arraste a vapor. Os óleos foram submetidos a 10 diferentes diluições $(1 / 9,2 / 8,3 / 7,4 / 6,5 / 5,6 / 4,7 / 3,8 / 2,1 / 9,1)$. A técnica utilizada foi o embebimento das amostras em discos absorventes estéreis que foram adicionados sobre ágar contendo os microrganismos, e posterior mensuração dos halos de inibição. Os resultados obtidos demonstraram que todos os óleos 
MELO, V.Q. et al. Avaliação in vitro de óleos essenciais na inibição de Staphylococcus aureus e Escherichia coli. PUBVET, Londrina, V. 5, N. 14, Ed. 161, Art. 1089, 2011.

essenciais nas concentrações testados não apresentaram características inibitórias frente à Escherichia coli ATCC 25922 e Staphylococcus aureus ATCC 25923.

\title{
Evaluation in vitro of essential oils in the inhibition of Staphylococcus aureus and Escherichia coli
}

\begin{abstract}
This work was carried through with the objective to evaluate the effect in vitro of essential oils in the inhibition of Escherichia coli ATCC 25922 and Staphylococcus aureus ATCC 25923. We tested the essential oils of rosemary (Rosmarinus officinalis), marjoran (Origanum marjorana L.), basil (Ocimum basilicum L.), eucalyptus (Eucalyptus citriodora), citronela (Cymbopogon nardus), grass-lemon (Cymbopogon citratus), previously extracted for the technique of drag the vapor. The oils had been submitted at 10 different dilutions $(1 / 9,2 / 8,3 / 7,4 / 6,5 / 5,6 / 4,7 / 3,8 / 2,1 / 9,1)$. The used technique was the embodiment of the samples in barren absorbent records that had been added on agar to contain the microorganisms and reading to subsequent of inhibition halos. The results had demonstrated that all the essential oils in the tested concentrations had not presented innibitory characteristics front to the Escherichia aureus coli ATCC 25922 and Staphylococcus aureus ATCC 25923.
\end{abstract}

\section{1- Introdução}

Os óleos essenciais estão associados a várias funções necessárias à sobrevivência dos vegetais em seu ecossistema e exercem papel fundamental na defesa contra microrganismos patogênicos. Na prática médica popular, existem relatos de sua utilização como agentes medicinais desde tempos remotos. Eles são líquidos voláteis, refringentes e de odor característico, 
MELO, V.Q. et al. Avaliação in vitro de óleos essenciais na inibição de Staphylococcus aureus e Escherichia coli. PUBVET, Londrina, V. 5, N. 14, Ed. 161, Art. 1089, 2011.

originados de um grande número de plantas como subprodutos do metabolismo secundário (SIANI et al., 2000).

Esses óleos têm despertado interesses comerciais de grandes grupos empresariais que visam incrementar seus lucros, principalmente no setor de cosméticos e alimentos. Adicionalmente, as empresas buscam diminuir o impacto ambiental já que os óleos são extraídos de partes de plantas (folhas, raízes, sementes, caules, entre outros) que ate então, apenas geravam resíduos para a indústria.

Os óleos essenciais vêm sendo utilizados com o intuito de inibir ou mesmo destruir microrganismos patogênicos encontrados no ambiente e em alimentos in natura ou processados. Recentemente, pesquisas confirmaram que determinados óleos essenciais, em diluições adequadas, são capazes de inibir o desenvolvimento micelial de fungos e colaborar para a obtenção de um alimento mais seguro e com maior durabilidade (PEREIRA et al., 2004).

O potencial antimicrobiano dos óleos essenciais, particularmente os extraídos de plantas medicinais, condimentos e especiarias de uso doméstico (alecrim, manjericão, manjerona, capim-limão, eucalipto, citronela, dentre outros) é sem dúvida a principal propriedade biológica dos óleos com aplicações em alimentos.

Objetivou-se com esse estudo verificar in vitro a eficiência dos óleos de alecrim (Rosmarinus officinalis), manjerona (Origanum majorana L.), manjericão (Ocimum basilicum L.), eucalipto (Eucalyptus citriodora), citronela (Cymbopogon nardus) e capim-limão (Cymbopogon citratus) na inibição de Escherichia coli ATCC 25922 e Staphylococcus aureus ATCC 25923.

\section{2 - Materiais e Métodos}

Foram utilizados óleos essenciais de alecrim (Rosmarinus officinalis), manjerona (Origanum majorana L.), manjericão (Ocimum basilicum L.), eucalipto (Eucalyptus citriodora), citronela (Cymbopogon nardus) e capimlimão (Cymbopogon citratus) com 100\% de pureza, obtidos por processo de 
destilação por arraste a vapor em baixa pressão, gentilmente cedido por Tekton - Óleos essenciais.

No laboratório, cada óleo essencial foi assepticamente diluído em álcool etílico nas seguintes concentrações: $1 / 9,2 / 8,3 / 7,4 / 6,5 / 5,6 / 4,7 / 3,8 / 2,1 / 9,1$.

Paralelamente, culturas puras com crescimento de 24 horas (fase estacionária de crescimento) de Staphylococcus aureus ATCC 25923 e Escherichia coli ATCC 25922 foram inoculadas em caldo BHI (infusão de cérebro e coração) e incubadas a $35^{\circ} \mathrm{C} \pm 1^{\circ} \mathrm{C}$ até alcançarem turvação equivalente a 0,5 na escala de MacFarland.

Essas culturas $(0,1 \mathrm{~mL})$ foram semeadas em duplicata com auxílio de swab na superfície de uma placa de Petri contendo agar Mueller Hinton. Após absorção das culturas pelo ágar, discos absorventes estéreis foram mergulhados separadamente nas diferentes diluições dos óleos essenciais de alecrim, manjerona, manjericão, eucalipto, capim-limão e citronela e depositado na superfície das placas. Foi utilizado como controle um disco mergulhado no álcool etílico utilizado para diluição.

As placas foram incubadas a $35^{\circ} \mathrm{C} \pm 1^{\circ} \mathrm{C}$ por 24 horas e, posteriormente, os halos de inibição foram medidos e anotados. Considerou-se como tamanho do halo de inibição a diferença entre medida verificada no disco controle e a diluição selecionada. Foram realizadas duas repetições para cada diluição selecionada e os resultados comparados.

\section{3 - Resultados e Discussão}

As medidas dos halos de inibição obtidas nas diferentes diluições selecionadas para o óleo essencial de alecrim demonstraram que essa substância não foi capaz de inibir in vitro o crescimento dos microrganismos testados. Esse resultado contradiz COELHO et al. (1997) que afirmam que o óleo essencial de alecrim possui propriedades anti-sépticas. Porém, estes autores não descrevem para qual microrganismo ou grupo esta substância é capaz de inibir. 
MELO, V.Q. et al. Avaliação in vitro de óleos essenciais na inibição de Staphylococcus aureus e Escherichia coli. PUBVET, Londrina, V. 5, N. 14, Ed. 161, Art. 1089, 2011.

Os halos médios de inibição $(\mathrm{mm})$ determinados para óleos essenciais de manjerona e manjericão nas diferentes diluições podem ser observados nas Tabelas 1 e 2.

A manjerona é um tempero muito utilizado na culinária e que, apesar do seu alto valor medicinal, atualmente tem sido pouco empregado na medicina popular. Seu óleo essencial vem despertando interesse por possuir atividade biológica (antibacteriana, antifúngica e antioxidante). Na indústria de alimentos, o óleo destilado tem larga aplicação, levando em conta sua grande estabilidade de conservação e ausência de contaminação microbiológica (MENEZES JUNIOR, 2005).

Nos resultados apresentados não foi descontado o tamanho do disco no álcool (1,22 cm para Escherichia coli e 2,36 cm para Staphylococcus aureus).

Tabela 1 - Média ponderada dos halos de inibição (tamanho do halo + disco em milímetro $\mathrm{mm}$ ) observados para os microrganismos testados frente a diferentes diluições do óleo de manjerona

\begin{tabular}{ccc}
\hline Diluição & Escherichia coli & Staphylococcus aureus \\
\hline $0,1 \mathrm{~mL}$ óleo $-0,9 \mathrm{~mL}$ álcool & 1,6 & 3,3 \\
$0,2 \mathrm{~mL}$ óleo $-0,8 \mathrm{~mL}$ álcool & 1,5 & 3,7 \\
$0,3 \mathrm{~mL}$ óleo $-0,7 \mathrm{~mL}$ álcool & 1,2 & 2 \\
$0,4 \mathrm{~mL}$ óleo $-0,6 \mathrm{~mL}$ álcool & 1,1 & 1,1 \\
$0,5 \mathrm{~mL}$ óleo $-0,5 \mathrm{~mL}$ álcool & 1,2 & 2,3 \\
$0,6 \mathrm{~mL}$ óleo $-0,4 \mathrm{~mL}$ álcool & 1,2 & $\mathrm{NR}$ \\
$0,7 \mathrm{~mL}$ óleo $-0,3 \mathrm{~mL}$ álcool & 1,3 & 2,9 \\
$0,8 \mathrm{~mL}$ óleo $-0,2 \mathrm{~mL}$ álcool & 1,3 & $\mathrm{NR}$ \\
$0,9 \mathrm{~mL}$ óleo $-0,1 \mathrm{~mL}$ álcool & 1,4 & 3,6 \\
1 mL óleo puro & 1,3 & 2,75 \\
\hline
\end{tabular}

NR=Não Realizado 
MELO, V.Q. et al. Avaliação in vitro de óleos essenciais na inibição de Staphylococcus aureus e Escherichia coli. PUBVET, Londrina, V. 5, N. 14, Ed. 161, Art. 1089, 2011.

Tabela 2 - Média ponderada dos halos de inibição (tamanho do halo + disco em milímetro $\mathrm{mm}$ ) observados para os microrganismos testados frente a diferentes diluições do óleo de manjericão

\begin{tabular}{ccc}
\hline Diluição & Escherichia coli & Staphylococcus aureus \\
\hline $0,1 \mathrm{~mL}$ óleo $-0,9 \mathrm{~mL}$ álcool & 1,6 & 2,7 \\
$0,2 \mathrm{~mL}$ óleo $-0,8 \mathrm{~mL}$ álcool & 1,4 & 3,4 \\
$0,3 \mathrm{~mL}$ óleo $-0,7 \mathrm{~mL}$ álcool & 1,3 & 1,85 \\
$0,4 \mathrm{~mL}$ óleo $-0,6 \mathrm{~mL}$ álcool & 1,1 & 1,75 \\
$0,5 \mathrm{~mL}$ óleo $-0,5 \mathrm{~mL}$ álcool & 1,1 & 3,35 \\
$0,6 \mathrm{~mL}$ óleo $-0,4 \mathrm{~mL}$ álcool & 1,2 & 2,8 \\
$0,7 \mathrm{~mL}$ óleo $-0,3 \mathrm{~mL}$ álcool & 1,7 & 2,55 \\
$0,8 \mathrm{~mL}$ óleo $-0,2 \mathrm{~mL}$ álcool & 1,3 & 3,9 \\
$0,9 \mathrm{~mL}$ óleo $-0,1 \mathrm{~mL}$ álcool & $\mathrm{NR}$ & 2,75 \\
1 mL óleo puro & 1,3 & 3,15 \\
\hline
\end{tabular}

NR=Não Realizado

Nas diferentes diluições do óleo essencial de eucalipto, as duas bactérias testadas cresceram de forma normal, não sofrendo nenhuma influência pela presença do óleo. O mesmo aconteceu quando o óleo essencial de citronela foi testado. Estes resultados não eram esperados já que o óleo de eucalipto é largamente utilizado na composição de desinfetantes (VITTI; BRITO, 1999). Também, o óleo de citronela, apesar de mais conhecido por sua ação repelente de insetos, é considerado anti-séptico e germicida (AMARAL, SILVA, 2003). Porém, neste estudo não foi observada inibição das bactérias testadas.

As médias dos halos de inibição para o óleo essencial de capim-limão estão contidas na Tabela 3.

Apesar do óleo essencial de capim-limão e suas diluições terem apresentado alguma inibição frente a Escherichia coli, não houve nenhum efeito sobre o crescimento de Staphylococcus aureus. Há relatos sobre a atividade fungistática desse óleo, porém, não existem relatos de seu uso como anti-séptico em infecções bacterianas (CRUZ et al., 2000). 
MELO, V.Q. et al. Avaliação in vitro de óleos essenciais na inibição de Staphylococcus aureus e Escherichia coli. PUBVET, Londrina, V. 5, N. 14, Ed. 161, Art. 1089, 2011.

Tabela 3 - Média ponderada dos halos de inibição (tamanho do halo + disco em milímetro $\mathrm{mm}$ ) observados para os microrganismos testados frente a diferentes diluições do óleo de capim-limão

\begin{tabular}{ccc}
\hline Diluição & Escherichia coli & Staphylococcus aureus \\
\hline $0,1 \mathrm{~mL}$ óleo $-0,9 \mathrm{~mL}$ álcool & 2,1 & Não houve características \\
$0,2 \mathrm{~mL}$ óleo $-0,8 \mathrm{~mL}$ álcool & 1,1 & de inibição pelo óleo \\
$0,3 \mathrm{~mL}$ óleo $-0,7 \mathrm{~mL}$ álcool & 1,3 & frente ao microrganismo. \\
$0,4 \mathrm{~mL}$ óleo $-0,6 \mathrm{~mL}$ álcool & 1,6 & Crescimento normal de \\
$0,5 \mathrm{~mL}$ óleo $-0,5 \mathrm{~mL}$ álcool & 1,15 & colônias. \\
$0,6 \mathrm{~mL}$ óleo $-0,4 \mathrm{~mL}$ álcool & 1,2 & \\
$0,7 \mathrm{~mL}$ óleo $-0,3 \mathrm{~mL}$ álcool & 2,1 & \\
$0,8 \mathrm{~mL}$ óleo $-0,2 \mathrm{~mL}$ álcool & 1,3 & \\
$0,9 \mathrm{~mL}$ óleo $-0,1 \mathrm{~mL}$ álcool & 1,9 & \\
$1 \mathrm{~mL}$ óleo puro & 2 & \\
\hline
\end{tabular}

Neste estudo não foi determinada atividade antimicrobiana significativa frente as duas espécies de bactérias testadas. Apesar disso, pesquisas confirmaram que determinados óleos essenciais, em diluições adequadas são capazes de inibir o desenvolvimento micelial de fungos (PEREIRA et al., 2004; SOUZA et al., 2004; SIANI et al., 2000).

\section{4 - Conclusão}

Todos os óleos testados no presente estudo não apresentaram características de inibição frente a Escherichia coli e Staphylococcus aureus. Nos casos onde foi observado halos de inibição, estes não foram considerados satisfatórios para uso diluído em alimentos com o objetivo de inibir o crescimento bacteriano.

Outros microrganismos poderão ser testados utilizando os mesmos óleos, visando uma possível aplicação em produtos alimentícios, assim como para inibir o desenvolvimento fúngico. 
MELO, V.Q. et al. Avaliação in vitro de óleos essenciais na inibição de Staphylococcus aureus e Escherichia coli. PUBVET, Londrina, V. 5, N. 14, Ed. 161, Art. 1089, 2011.

\section{5 - Referências Bibliográficas}

AMARAL, C. L. P.; SILVA, A. B. Melhoramento biotecnológico de plantas medicinais. Biotecnologia Ciência e Desenvolvimento, a. 6, n. 30,2003.

COELHO, L. A. P., OliVeirA, J. V., PINTO, J. C. Modelagem e Simulação do processo de extração supercrítica do óleo essencial de alecrim. Ciência e Tecnologia Alimentícia, vol. 17, n. 4 Campinas, 1997.

CRUZ, M. E. S., NOZAKI, M. H., BATISTA, M. A. Plantas medicinais. Biotecnologia Ciência e Desenvolvimento, a.3, n. 15, 2000.

MENeZeS JUNIOR, A. Plantas Medicinais. Peregrino Comunicação Visual, a. VII, n. 78. Ribeirão Preto, 2005.

PEREIRA, R. S., SUMITA, T. C., FURLAN, M.R., JORGE, A. O. C., BUENO, M. Atividade antibacteriana de óleos essenciais em cepas isoladas de infecção urinária. Revista de Saúde Publica, v. 38, n. 2. São Paulo, 2004.

SIANI, A. C.; SAMPAIO, A. L. F.; SOUSA, M. C. de; HENRIQUES, M. G.,M. 0.;RAMOS, M. F. de S. Óleos essenciais. Biotecnologia Ciência e Desenvolvimento, ano 3, n. 16. São Paulo, 2000. p. 38-43.

SOUZA, S. M. C. de; PEREIRA, M. C.; ANGÉLiCO, C. L. PIMENTA, C. J. Avaliação de óleos essenciais de condimentos sobre o desenvolvimento micelial de fungos associados a produtos de panificação. Ciências Agrotécnicas, v. 28, n. 3. Lavras, 2004. p. 685-690.

VITTI, A. M. S.; BRITO, J. O. Avaliação do rendimento do teor de citronela do óleo essencial de procedências e raças locais de Eucalyptus citriodora. Scientia Florestalis, n. 56, 1999, p. 145-154. 